\title{
A NOTE ON MARKET COVERAGE IN VERTICAL DIFFERENTIATION MODELS WITH FIXED COSTS
}

\author{
Pei-Cheng Liao \\ Department of Accounting, National Taiwan University, Taiwan
}

\begin{abstract}
With fixed costs of quality improvement, we find that a covered market outcome with an interior solution in the price stage is not a Nash equilibrium. When the degree of consumer heterogeneity is high (low) enough, an uncovered market outcome (a covered market outcome with a corner solution in the price stage) is the only Nash equilibrium. When the degree of consumer heterogeneity is moderate, both of the two market outcomes are Nash equilibria, but an uncovered market outcome yields higher social welfare than a covered market outcome with a corner solution in the price stage.
\end{abstract}

Keywords: endogenous market outcome, fixed quality costs, market coverage

JEL classification numbers: L11, L13

\section{INTRODUCTION}

Since the classical works by Gabszewicz and Thisse (1979) and Shaked and Sutton (1982), the issue on quality competition between firms has been widely analysed in the literature. The early works implicitly assume that the market is either covered or uncovered. Motta (1993) points out

Correspondence: Department of Accounting, National Taiwan University, No. 1, Sec. 4, Roosevelt Rd, Taipei, 106, Taiwan. Tel: +886-2-33661127; Fax: +886-2-23638038; Email: pcliao@ntu.edu.tw. I am grateful to the journal editor, Klaus Zauner, and two anonymous referees for their invaluable comments and suggestions. The remaining errors are my responsibility. I gratefully acknowledge the financial support of the National Science Council, Taiwan, under grant no. NSC 93-2415-H-002-015. 
that the Cournot case can be analysed only under partial market coverage because the demand functions cannot be inverted under full market coverage. Das and Donnenfeld (1989), Valletti (2000) and Herguera et al. (2000), for example, analyse the effects of quantity restriction (quota) and/or quality restriction (minimum quality standard) on the duopolists with Cournot competition, and the market is uncovered in their models. Herguera et al. (2002) analyse the tariff policy in a Cournot duopoly model, where the market is uncovered. Motta (1993) also points out that, with the assumption that consumers are uniformly distributed on the interval $[0,1]$, the market is implicitly uncovered because some consumers will never buy the product. ${ }^{1}$ With such an assumption, the market is uncovered in Ronnen (1991), Motta (1993), Polavarapu and Vaidya (1996a, b), Aoki and Prusa (1996), Lehmann-Grube (1997), Lutz (2000), Lutz et al. (2000) and Zhou et al. (2002), for example. Moorthy (1988) interprets 'buying nothing' as the choice of a substitute of quality zero and price zero, or as buying another kind of product. ${ }^{2}$ In his model, although consumers are assumed to be uniformly distributed on the interval $[a, b], b>a>0$, the market is uncovered with such an interpretation. On the other hand, some papers, for example, Crampes and Hollander(1995), Boom (1995), Ecchia and Lambertini (1997), Maxwell (1998), Wang and Yang (2001), Wang (2003), analyse the Bertrand case with the assumption that the markets is covered.

Without assuming ex ante that the market is covered or uncovered, Wauthy (1996) shows that covered or uncovered markets are endogenous outcomes of the quality game, and the market outcome depends on the degree of consumer heterogeneity. Wauthy (1996) typically assumes that the costs of improving quality are zero. ${ }^{3}$ Under the assumption of zero costs, it is costless to produce any quality level of a product. But in reality quality improvements do cost, and it is generally believed that it is more costly to produce a higher-quality product. With the same (zero) cost, it is also hard to explain why the duopolists would produce differentiated goods, and why one firm chooses to be the highquality firm and the other the low-quality firm. Moreover, Wauthy (1996) imposes an arbitrary upper bound on quality, and thus the high-quality firm always chooses this highest feasible quality independently of the low-quality firm's choice. In this paper, we relax the assumption of zero costs and assume that firms incur fixed costs to improve quality, and a higher-quality product costs more to produce than a lower-quality one. Following Wauthy (1996), we re-examine the market outcome of the game in which the duopolists choose the quality levels in the first

\footnotetext{
${ }^{1}$ It is also the case for the models with consumers uniformly distributed on the interval [0, $b], b>0$.

${ }^{2}$ For example, a consumer buying nothing in an automobile market may buy a bicycle.

${ }^{3}$ The same was assumed in Shaked and Sutton (1982), Choi and Shin (1992) and Wang and Yang (2001).
}

(C) 2008 The Author. Journal compilation (C) 2008 Blackwell Publishing Ltd and the Board of Trustees of the Bulletin of Economic Research. 
stage, and compete in prices in the second stage. ${ }^{4}$ Unlike Wauthy (1996), we find that a covered market outcome with an interior solution in the price stage is not an equilibrium. Thus, the analysis under this market configuration becomes inappropriate and irrelevant in the presence of fixed quality costs. We find that the market is uncovered at equilibrium when $\theta / \theta>4.7226$, and the market is covered with a corner solution in the price stage when $2<\bar{\theta} / \underline{\theta}<4.7125$. When $4.7125 \leq \bar{\theta} / \underline{\theta} \leq 4.7226$, the two market outcomes are both Nash equilibria. ${ }^{5}$ Taking social welfare into consideration, we find that when $4.7125 \leq \bar{\theta} / \underline{\theta} \leq 4.7226$, an uncovered market outcome yields higher social welfare than a covered market outcome with a corner solution in the price stage.

The remainder of the paper is organized as follows. Section II describes the model with fixed costs of quality improvement. Sections III and IV analyse the equilibrium of the game by assuming that the market outcome is exogenous and endogenous to the firms, respectively. Section V concludes the paper.

\section{FIXED COSTS OF QUALITY IMPROVEMENT}

We use a vertical product differentiation model that was developed along the line of Gabszewicz and Thisse (1979), Shaked and Sutton (1982) and Tirole (1988). Two firms supply a vertically differentiated good, each with a quality denoted by $s_{i}, i=H, L$, and $s_{H}>s_{L}>0$. Each firm incurs a fixed cost which is quadratic in quality with the form $s_{i}^{2} / 2, i=H, L$. There is a continuum of consumers indexed by $\theta$, uniformly distributed in the interval $[\underline{\theta}, \bar{\theta}]$ with unit density, $\bar{\theta}-\underline{\theta}=1,{ }^{6}$ and $\bar{\theta}>\underline{\theta} \geq 0$. The parameter $\theta$ represents consumers' marginal willingness to pay for quality, or the reciprocal of the marginal utility of income. Consumer $\theta$ has unit demand for the good and his utility function is

$$
U= \begin{cases}\theta s_{i}-p_{i} & \begin{array}{l}
\text { if buying one unit of the good with } \\
\text { quality } s_{i} \text { at price } p_{i}, i=H, L \\
0
\end{array} \\
\text { otherwise }\end{cases}
$$

We consider the following two-stage game. In stage one, the firms simultaneously determine the quality levels of their products. In stage

\footnotetext{
${ }^{4}$ The order of the moves is consistent with the assumption of fixed costs because the quality choice is irreversible. Moreover, we analyse the Bertrand case rather than the Cournot case because the latter can only be analysed in an uncovered market, as pointed out by Motta (1993).

${ }^{5}$ Wauthy (1996) finds that when $\bar{\theta} / \theta>8.6581$, the market is uncovered; when $5 \leq \bar{\theta} / \theta \leq$ 8.6581 , the market is covered with a corner solution in the price game; when $2<\bar{\theta} / \theta<5$, the market is covered with an interior solution in the price game.

${ }^{6}$ It is a general assumption in the literature. We make this assumption for simplification, and more importantly, we are able to compare our results with Motta (1993).

(C) 2008 The Author. Journal compilation (C) 2008 Blackwell Publishing Ltd and the Board of Trustees of the Bulletin of Economic Research.
} 
two, they compete in prices. Consumers, perfectly informed about the products and prices of the two firms, purchase the product from the firm that generates a higher utility level. Let $\hat{\theta}_{1}$ be the consumer who is indifferent to the product produced by either firm, so $\hat{\theta}_{1}=\left(p_{H}-\right.$ $\left.p_{L}\right) /\left(s_{H}-s_{L}\right)$. Let $\hat{\theta}_{2}$ be the consumer who is indifferent between buying the low-quality good and buying nothing at all, so $\hat{\theta}_{2}=p_{L} / s_{L}$. Consumer $\theta$ with $\theta \geq \hat{\theta}_{1}$ and $\hat{\theta}_{1}>\theta \geq \hat{\theta}_{2}$ will purchase the high-quality good and the low-quality good, respectively. Consumer $\theta$ with $\theta<\hat{\theta}_{2}$ will buy nothing at all. If $\hat{\theta}_{2}>\underline{\theta}$, the market is uncovered because the portion of the market $\left[\underline{\theta}, \hat{\theta}_{2}\right)$ is not served by either firm. If $\hat{\theta}_{2} \leq \underline{\theta}$, the market is covered in the sense that every consumer in the market consumes either good rather than nothing at all.

Without assuming ex ante that the market is covered or uncovered, Wauthy (1996) shows that covered or uncovered markets are endogenous outcomes of the quality game. There are four possible cases at the price stage: uncovered market, covered market with a corner solution, covered market with an interior solution and pre-empted market. Since we are interested in a duopoly model in which both firms supply a positive quantity of output and earn a non-negative profit, our analysis is limited to the first three cases. The price equilibrium in the second stage in our model is the same as that shown in Wauthy (1996). According to Wauthy (1996), the Nash equilibrium in prices and associated market outcomes depend on the degree of population heterogeneity $(\underline{\theta}, \bar{\theta})$ and the degree of product differentiation $\left(s_{L}, s_{H}\right)$. Denote $\mu=s_{H} / s_{L}, \gamma=\bar{\theta} / \underline{\theta}$, and the conditions for each market configuration are illustrated as follows. ${ }^{7}$

I. The market is uncovered in the price stage when $4+[3 /(\mu-1)]<$ $\gamma<\infty$.

II. The market is covered with a corner solution in the price stage when

$$
2+[3 /(\mu-1)] \leq \gamma \leq 4+[3 /(\mu-1)]
$$

III. The market is covered with an interior solution in the price stage when

$$
2<\gamma<2+[3 /(\mu-1)]
$$

\section{EXOGENOUS MARKET OUTCOME}

For the time being, we assume that the market outcome is exogenous to the firms, and we derive the equilibrium of the game for each market configuration.

\footnotetext{
${ }^{7}$ See Wauthy (1996).

(C) 2008 The Author. Journal compilation (C) 2008 Blackwell Publishing Ltd and the Board of Trustees of the Bulletin of Economic Research.
} 


\section{Case I: An uncovered market}

Suppose that the market is ex ante assumed to be uncovered. Denote the variables in this case with a double asterisk. With the equilibrium prices in the second stage derived as Wauthy (1996), we have the corresponding profits for the high-quality and low-quality firms, respectively:

$$
\pi_{H}^{* *}=\frac{4 \bar{\theta}^{2} s_{H}^{2}\left(s_{H}-s_{L}\right)}{\left(4 s_{H}-s_{L}\right)^{2}}-\frac{1}{2} s_{H}^{2} \quad \pi_{L}^{* *}=\frac{\bar{\theta}^{2} s_{H} s_{L}\left(s_{H}-s_{L}\right)}{\left(4 s_{H}-s_{L}\right)^{2}}-\frac{1}{2} s_{L}^{2}
$$

The best replies for the high-quality and low-quality firms, given the other firm's quality, are derived, respectively, in the following:

$$
\begin{gathered}
s_{H}^{* *}\left(s_{L}\right): \frac{4 \bar{\theta}^{2} s_{H}\left(4 s_{H}^{2}-3 s_{H} s_{L}+2 s_{L}^{2}\right)}{\left(4 s_{H}-s_{L}\right)^{3}}-s_{H}=0 \\
s_{L}^{* *}\left(s_{H}\right): \frac{\bar{\theta}^{2} s_{H}^{2}\left(4 s_{H}-7 s_{L}\right)}{\left(4 s_{H}-s_{L}\right)^{3}}-s_{L}=0
\end{gathered}
$$

Solving the two first-order conditions (1) and (2) simultaneously, Motta (1993) has shown that $\mu^{* *}=s_{H}^{* *} / s_{L}^{* *}=5.2512$, which is constant regardless of $\gamma$. The condition for the assumption that the market is uncovered is then $\gamma>4+\left[3 /\left(\mu^{* *}-1\right)\right]=4.7057$. Substituting $\mu^{* *}$ back into (1) and (2) yields

$$
\begin{gathered}
s_{H}^{* *}=\frac{4 \underline{\theta}^{2} \gamma^{2} \mu^{* *}\left(4 \mu^{* * 2}-3 \mu^{* *}+2\right)}{\left(4 \mu^{* *}-1\right)^{3}} \\
s_{L}^{* *}=\frac{\theta^{2} \gamma^{2} \mu^{* * 2}\left(4 \mu^{* *}-7\right)}{\left(4 \mu^{* *}-1\right)^{3}}
\end{gathered}
$$

The corresponding equilibrium prices, quantities and profits are ${ }^{8}$

$$
\begin{gathered}
p_{H}^{* *}=\frac{8 \underline{\theta}^{3} \gamma^{3} \mu^{* *}\left(\mu^{* *}-1\right)\left(4 \mu^{* * 2}-3 \mu^{* *}+2\right)}{\left(4 \mu^{* *}-1\right)^{4}} \\
p_{L}^{* *}=\frac{\underline{\theta}^{3} \gamma^{3} \mu^{* * 2}\left(\mu^{* *}-1\right)\left(4 \mu^{* *}-7\right)}{\left(4 \mu^{* *}-1\right)^{4}} \\
q_{H}^{* *}=\bar{\theta}-\hat{\theta}_{1}=\frac{2 \underline{\theta} \gamma \mu^{* *}}{4 \mu^{* *}-1}
\end{gathered}
$$

${ }^{8} \hat{\theta}_{1}=\left(p_{H}^{* *}-p_{L}^{* *}\right) /\left(s_{H}^{* *}-s_{L}^{* *}\right)=\underline{\theta} \gamma\left(2 \mu^{* *}-1\right) /\left(4 \mu^{* *}-1\right) \quad$ and $\quad \hat{\theta}_{2}=p_{L}^{* *} / s_{L}^{* *}=$ $\underline{\theta} \gamma\left(\mu^{* *}-1\right) /\left(4 \mu^{* *}-1\right)$.

(C) 2008 The Author. Journal compilation (C) 2008 Blackwell Publishing Ltd and the Board of Trustees of the Bulletin of Economic Research. 


$$
\begin{gathered}
q_{L}^{* *}=\hat{\theta}_{1}-\hat{\theta}_{2}=\frac{\underline{\theta} \gamma \mu^{* *}}{4 \mu^{* *}-1} \\
\pi_{H}^{* *}=\frac{8 \underline{\theta}^{4} \gamma^{4} \mu^{* * 3}\left(4 \mu^{* *}-7\right)\left(4 \mu^{* * 2}-3 \mu^{* *}+2\right)}{\left(4 \mu^{* *}-1\right)^{6}} \\
\pi_{L}^{* *}=\frac{\underline{\theta}^{4} \gamma^{4} \mu^{* * 3}\left(4 \mu^{* *}-7\right)\left(4 \mu^{* * 2}-3 \mu^{* *}+2\right)}{2\left(4 \mu^{* *}-1\right)^{6}}
\end{gathered}
$$

Case II: A covered market with a corner solution in the price stage

Suppose that the market is ex ante assumed to be covered with a corner solution in the price stage. Denote the variables in this case with a superscript $c$. The market is just covered with $p_{L}^{c}=\underline{\theta} s_{L}$ and $p_{H}^{c}=\left[\theta s_{L}+\bar{\theta}\left(s_{H}-s_{L}\right)\right] / 2$ chosen in the second stage. ${ }^{9}$ In the first stage, the firms choose qualities to maximize their own profits, which are given by

$$
\begin{gathered}
\pi_{H}^{c}=\frac{\left[\bar{\theta} s_{H}-(\bar{\theta}-\underline{\theta}) s_{L}\right]^{2}}{4\left(s_{H}-s_{L}\right)}-\frac{1}{2} s_{H}^{2} \\
\pi_{L}^{c}=\frac{\underline{\theta} s_{L}\left[(\bar{\theta}-2 \underline{\theta}) s_{H}-(\bar{\theta}-\underline{\theta}) s_{L}\right]}{2\left(s_{H}-s_{L}\right)}-\frac{1}{2} s_{L}^{2}
\end{gathered}
$$

Thus, the best replies for the high-quality and low-quality firms, given the other firm's quality, are derived, respectively, in the following:

$$
\begin{gathered}
s_{H}^{c}\left(s_{L}\right): \frac{\left[\bar{\theta}^{2}\left(s_{H}-s_{L}\right)^{2}-\underline{\theta}^{2} s_{L}^{2}\right]}{4\left(s_{H}-s_{L}\right)^{2}}-s_{H}=0 \\
s_{L}^{c}\left(s_{H}\right): \frac{\left[\underline{\theta}(\bar{\theta}-\underline{\theta})\left(s_{H}-s_{L}\right)^{2}-\underline{\theta}^{2} s_{H}^{2}\right]}{2\left(s_{H}-s_{L}\right)^{2}}-s_{L}=0
\end{gathered}
$$

Solving the two first-order conditions (5) and (6) simultaneously yields

$$
(2 \gamma-4) \mu^{3}+\left(4-4 \gamma-\gamma^{2}\right) \mu^{2}+\left(2 \gamma^{2}+2 \gamma-2\right) \mu+\left(1-\gamma^{2}\right)=0
$$

Given a value of $\gamma$, we can derive the solution $\mu^{c}(\gamma)$ from (7), and the pair of $\left(\gamma, \mu^{c}(\gamma)\right)$ has to satisfy the following condition for the

${ }^{9}$ As Wauthy (1996) explains, there is a range of parameter values where neither condition $p_{L}^{* *} / s_{L}>\underline{\theta}$ nor $p_{L}^{*} / s_{L}<\underline{\theta}$ holds, i.e., when $p_{L}^{* *} / s_{L} \leq \underline{\theta}$ and $p_{L}^{*} / s_{L} \geq \underline{\theta}$. Under an uncovered market assumption, $\bar{\partial} \pi_{L} / \partial p_{L}<0$ at $p_{L}=\underline{\theta} s_{L}$; under a covered market assumption, $\partial \pi_{L} / \partial p_{L}>0$ at $p_{L}=\underline{\theta} s_{L}$. Thus, for these values of the parameters, a corner solution in the price stage prevails where the low-quality firm chooses $p_{L}^{c}=\underline{\theta} s_{L}$, the price that makes a consumer of type $\underline{\theta}$ indifferent between buying the low-quality good and not buying at all. See more details in Appendix A.

(C) 2008 The Author. Journal compilation (C) 2008 Blackwell Publishing Ltd and the Board of Trustees of the Bulletin of Economic Research. 
assumption that the market is covered with a corner solution in the price stage:

$$
2+\frac{3}{\mu^{c}(\gamma)-1} \leq \gamma \leq 4+\frac{3}{\mu^{c}(\gamma)-1}
$$

Since $\mu^{c}(\gamma)$ is an implicit function of $\gamma$, we use numerical simulations to get the solution and find that $2<\gamma \leq 4.7301$ and $\mu^{c}(\gamma) \geq 5.1085$.

Substituting $\left(\gamma, \mu^{c}(\gamma)\right)$ back into (5) and (6) yields the equilibrium qualities:

$$
\begin{gathered}
s_{H}^{c}=\frac{\theta^{2}}{4}\left[\gamma^{2}-\left(\frac{1}{\mu^{c}(\gamma)-1}\right)^{2}\right] \\
s_{L}^{c}=\frac{\theta^{2}}{2}\left[\gamma-1-\left(\frac{\mu^{c}(\gamma)}{\mu^{c}(\gamma)-1}\right)^{2}\right]
\end{gathered}
$$

The corresponding equilibrium prices, quantities and profits are ${ }^{10}$

$$
\begin{gathered}
p_{H}^{c}=\frac{\frac{\theta}{3}^{3}}{4}\left[\gamma\left(\mu^{c}(\gamma)-1\right)+1\right]\left[\gamma-1-\left(\frac{\mu^{c}(\gamma)}{\mu^{c}(\gamma)-1}\right)^{2}\right] \\
p_{L}^{c}=\frac{\underline{\theta}^{3}}{2}\left[\gamma-1-\left(\frac{\mu^{c}(\gamma)}{\mu^{c}(\gamma)-1}\right)^{2}\right] \\
q_{H}^{c}=\bar{\theta}-\hat{\theta}_{1}=\frac{\theta}{2}\left(\gamma+\frac{1}{\mu^{c}(\gamma)-1}\right) \\
q_{L}^{c}=\hat{\theta}_{1}-\underline{\theta}=\frac{\theta}{2}\left(\gamma-2-\frac{1}{\mu^{c}(\gamma)-1}\right) \\
\times\left[\left(\gamma+\frac{1}{\mu^{c}(\gamma)-1}\right)^{2}+8-4 \gamma+\frac{8}{\mu^{c}(\gamma)-1}\right] \\
\pi_{L}^{c}=\frac{\theta^{4}}{32}\left(\gamma+\frac{1}{\mu^{c}(\gamma)-1}\right)^{2} \\
{\left[\gamma-2+\left(\frac{1}{\mu^{c}(\gamma)-1}\right)^{2}\right]\left[\gamma-1-\left(\frac{\mu^{c}(\gamma)}{\mu^{c}(\gamma)-1}\right)^{2}\right]}
\end{gathered}
$$

Case III: A covered market with an interior solution in the price stage Suppose that the market is ex ante assumed to be covered with an interior solution in the price stage. Denote the variables in this case with an

$$
{ }^{10} \hat{\theta}_{1}=\underline{\theta}\left[\gamma-1 /\left(\mu^{c}(\gamma)-1\right)\right] / 2 .
$$

(C) 2008 The Author. Journal compilation (C) 2008 Blackwell Publishing Ltd and the Board of Trustees of the Bulletin of Economic Research. 
asterisk. The equilibrium prices in the second stage are $p_{H}^{*}=(2 \bar{\theta}-$ $\underline{\theta})\left(s_{H}-s_{L}\right) / 3$ and $p_{L}^{*}=(\bar{\theta}-2 \underline{\theta})\left(s_{H}-s_{L}\right) / 3 .{ }^{11}$ In the first stage, the firms choose qualities to maximize their own profits, which are given by

$$
\begin{aligned}
\pi_{H}^{*} & =\frac{(2 \bar{\theta}-\underline{\theta})^{2}\left(s_{H}-s_{L}\right)}{9}-\frac{1}{2} s_{H}^{2} \\
\pi_{L}^{*} & =\frac{(\bar{\theta}-2 \underline{\theta})^{2}\left(s_{H}-s_{L}\right)}{9}-\frac{1}{2} s_{L}^{2}
\end{aligned}
$$

The best replies of the high-quality and low-quality firms are $s_{H}^{*}\left(s_{L}\right)=$ $(2 \bar{\theta}-\underline{\theta})^{2} / 9$ and $s_{L}^{*}\left(s_{H}\right)=s_{H}(\bar{\theta}-2 \underline{\theta}) /(\bar{\theta}+\underline{\theta})$, respectively. Thus, the equilibrium qualities are

$$
\begin{gathered}
s_{H}^{*}=\frac{(2 \bar{\theta}-\underline{\theta})^{2}}{9}=\frac{\frac{\theta}{2}^{2}(2 \gamma-1)^{2}}{9} \\
s_{L}^{*}=\frac{(2 \bar{\theta}-\underline{\theta})^{2}(\bar{\theta}-2 \underline{\theta})}{9(\bar{\theta}+\underline{\theta})}=\frac{\underline{\theta}^{2}(2 \gamma-1)^{2}(\gamma-2)}{9(\gamma+1)}
\end{gathered}
$$

The corresponding equilibrium prices, quantities and profits are ${ }^{12}$

$$
\begin{gathered}
p_{H}^{*}=\frac{\underline{\theta}(2 \bar{\theta}-\underline{\theta})^{3}}{9(\bar{\theta}+\theta)}=\frac{\underline{\theta}^{3}(2 \gamma-1)^{3}}{9(\gamma+1)} \\
p_{L}^{*}=\frac{\underline{\theta}(2 \bar{\theta}-\underline{\theta})^{2}(\bar{\theta}-2 \underline{\theta})}{9(\bar{\theta}+\underline{\theta})}=\frac{\underline{\theta}^{3}(2 \gamma-1)^{2}(\gamma-2)}{9(\gamma+1)} \\
q_{H}^{*}=\bar{\theta}-\hat{\theta}_{1}=\frac{2 \bar{\theta}-\underline{\theta}}{3}=\frac{\underline{\theta}(2 \gamma-1)}{3} \\
q_{L}^{*}=\hat{\theta}_{1}-\underline{\theta}=\frac{\bar{\theta}-2 \underline{\theta}}{3}=\frac{\underline{\theta}(\gamma-2)}{3} \\
\pi_{H}^{*}=\frac{(2 \bar{\theta}-\underline{\theta})^{4}(5 \underline{\theta}-\bar{\theta})}{162(\bar{\theta}+\underline{\theta})}=\frac{\underline{\theta}^{4}(2 \gamma-1)^{4}(5-\gamma)}{162(\gamma+1)} \\
\pi_{L}^{*}=\frac{(2 \bar{\theta}-\underline{\theta})^{2}(\bar{\theta}-2 \underline{\theta})^{2}\left(5 \underline{\theta}^{2}+10 \bar{\theta} \underline{\theta}-4 \bar{\theta}^{2}\right)}{162\left(\bar{\theta}+\underline{\theta}^{2}\right.} \\
=\frac{\underline{\theta}^{4}(2 \gamma-1)^{2}(\gamma-2)^{2}\left(5+10 \gamma-4 \gamma^{2}\right)}{162(\gamma+1)^{2}}
\end{gathered}
$$

To insure that each firm earns a non-negative profit, $5-\gamma \geq$ 0 and $5+10 \gamma-4 \gamma^{2} \geq 0$ have to be satisfied. Thus, the condition for the

${ }^{11}$ See more details in Appendix A.

${ }^{12} \hat{\theta}_{1}=(\bar{\theta}+\underline{\theta}) / 3$.

(C) 2008 The Author. Journal compilation (C) 2008 Blackwell Publishing Ltd and the Board of Trustees of the Bulletin of Economic Research. 
assumption that the market is covered with an interior solution in the price stage is $2<\gamma \leq 2.9270$.

\section{ENDOGENOUS MARKET OUTCOME}

Now suppose that the market outcome is endogenous to the firms. We have derived each firm's quality best reply, given the other firm's quality, region by region in Section III. In order to characterize quality equilibrium, we need to compare equilibrium payoffs as a function of the other's quality, and along best reply candidates across regions we then characterize the 'global' best reply for each firm. Finally by using this, we characterize quality equilibrium.

Across the regions defining both cases II and III, if a covered market outcome with an interior solution in the price stage was an equilibrium, neither firm would deviate from $s_{i}^{*}\left(s_{j}^{*}\right)$ to $s_{i}^{c}\left(s_{j}^{*}\right)$ when the other firm chooses $s_{j}^{*}, i, j=H, L$, and $i \neq j$. Given $s_{H}^{*}=(2 \bar{\theta}-\underline{\theta})^{2} / 9$, define $\mu_{L}^{c}=s_{H}^{*} / s_{L}^{c}\left(s_{H}^{*}\right)$ and $\mu_{L}^{*}=s_{H}^{*} / s_{L}^{*}\left(s_{H}^{*}\right)=(\bar{\theta}+\underline{\theta}) /(\bar{\theta}-2 \underline{\theta})$. It can be shown that $s_{L}^{*}\left(s_{H}^{*}\right)>s_{L}^{c}\left(s_{H}^{*}\right),{ }^{13}$ so $2+\left[3 /\left(\mu_{L}^{c}-1\right)\right]<\overline{2}+\left[3 /\left(\mu_{L}^{*}-\right.\right.$ $1)]=\bar{\theta} / \underline{\theta}$, meaning that within the region defining $s_{L}^{*}\left(s_{H}^{*}\right), s_{L}^{c}\left(s_{H}^{*}\right)$ is also defined. Since $\pi_{L}^{c}\left(s_{L}^{c}\left(s_{H}\right)\right)>\pi_{L}^{c}\left(s_{L}^{*}\left(s_{H}\right)\right)=\pi_{L}^{*}\left(s_{L}^{*}\left(s_{H}\right)\right),{ }^{14} s_{L}^{c}\left(s_{H}\right)$ dominates $s_{L}^{*}\left(s_{H}\right)$, implying that the low-quality firm will deviate from $s_{L}^{*}\left(s_{H}^{*}\right)$ to $s_{L}^{c}\left(s_{H}^{*}\right)$ when the high-quality firm chooses $s_{H}^{*}$. Thus, a covered market outcome with an interior solution in the price stage is not an equilibrium.

Proposition 1. Suppose that the market outcome is endogenous to the firms. With fixed costs of quality improvement, a covered market outcome with an interior solution in the price stage is not an equilibrium.

On the other hand, across the regions defining both cases II and III, for $\left(s_{H}^{c}=s_{H}^{c}\left(s_{L}^{c}\right), s_{L}^{c}=s_{L}^{c}\left(s_{H}^{c}\right)\right)$ and a covered market outcome with a corner solution in the price stage to be an equilibrium, we have to show that neither firm will deviate from $s_{i}^{c}\left(s_{j}^{c}\right)$ to $s_{i}^{*}\left(s_{j}^{c}\right)$ when the other firm chooses $s_{j}^{c}$. We just showed that $s_{L}^{c}\left(s_{H}\right)$ dominates $s_{L}^{*}\left(s_{H}\right)$, so the low-quality firm will choose $s_{L}^{c}\left(s_{H}^{c}\right)$ rather than $s_{L}^{*}\left(s_{H}^{c}\right)$ when the high-quality firm chooses $s_{H}^{c}$. As to the high-quality firm, it can be shown that $s_{H}^{*}\left(s_{L}\right)>s_{H}^{c}\left(s_{L}\right),{ }^{15}$ so $2+\left[3 /\left(\mu_{H}^{*}-1\right)\right]<2+\left[3 /\left(\mu_{H}^{c}-1\right)\right]$, where $\mu_{H}^{c}=s_{H}^{c}\left(s_{L}\right) / s_{L}$ and $\mu_{H}^{*}=s_{H}^{*}\left(s_{L}\right) / s_{L}$, meaning that the region defining $s_{H}^{*}\left(s_{L}\right)$ does not overlap the region defining $s_{H}^{c}\left(s_{L}\right)$. Thus, when $2+\left[3 /\left(\mu_{H}^{c}-1\right)\right] \leq \bar{\theta} / \underline{\theta} \leq$

${ }^{13}$ See Appendix B.

${ }^{14}$ See Appendix C.

${ }^{15}$ See Appendix D.

(C) 2008 The Author. Journal compilation (C) 2008 Blackwell Publishing Ltd and the Board of Trustees of the Bulletin of Economic Research. 
$4+\left[3 /\left(\mu_{H}^{* *}-1\right)\right],{ }^{16}$ where $\mu_{H}^{* *}=s_{H}^{* *}\left(s_{L}\right) / s_{L}$, only $s_{H}^{c}\left(s_{L}\right)$ is defined, so the best reply of the high-quality firm is $s_{H}^{c}\left(s_{L}^{c}\right)$ when the low-quality firm chooses $s_{L}^{c}$. Therefore, a covered market outcome with a corner solution in the price stage is a Nash equilibrium, in which the firms choose $s_{H}^{c}=$ $s_{H}^{c}\left(s_{L}^{c}\right)$ and $s_{L}^{c}=s_{L}^{c}\left(s_{H}^{c}\right)$, respectively, as shown in (8), in the quality stage.

Now we turn to the regions defining both cases I and II. For $\left(s_{H}^{c}=\right.$ $\left.s_{H}^{c}\left(s_{L}^{c}\right), s_{L}^{c}=s_{L}^{c}\left(s_{H}^{c}\right)\right)$ and a covered market outcome with a corner solution in the price stage to be an equilibrium, we have to show that neither firm will deviate from $s_{i}^{c}\left(s_{j}^{c}\right)$ to $s_{i}^{* *}\left(s_{j}^{c}\right)$ when the other firm chooses $s_{j}^{c}$. Since $\pi_{i}^{c}\left(s_{i}^{c}\left(s_{j}^{c}\right)\right)$ and $\pi_{i}^{* *}\left(s_{i}^{* *}\left(s_{j}^{c}\right)\right)$ are implicit functions of $\bar{\theta} / \underline{\theta}$ and the ranking of them depends on $\bar{\theta} / \underline{\theta}$, we use numerical simulations to compare them and we have the following findings. First, given $s_{H}^{c}$, when $2<\bar{\theta} / \underline{\theta} \leq 4+\left[3 /\left(\mu_{L}^{* *}-1\right)\right]=4.7159$, where $\mu_{L}^{* *}=s_{H}^{c} / s_{L}^{* *}\left(s_{H}^{c}\right)$, only $s_{L}^{c}\left(s_{H}^{c}\right)$ is defined, so the best reply of the low-quality firm is $s_{L}^{c}\left(s_{H}^{c}\right)$. When $4.7159=4+\left[3 /\left(\mu_{L}^{* *}-1\right)\right]<\bar{\theta} / \underline{\theta} \leq$ $4+\left[3 /\left(\mu_{L}^{c}-1\right)\right]=4.7301$, where $\mu_{L}^{c}=s_{H}^{c} / s_{L}^{c}\left(s_{H}^{c}\right)$, both $s_{L}^{c}\left(s_{H}^{c}\right)$ and $s_{L}^{* *}\left(s_{H}^{c}\right)$ are defined, and $\pi_{L}^{c}\left(s_{L}^{c}\left(s_{H}^{c}\right)\right)>\pi_{L}^{* *}\left(s_{L}^{* *}\left(s_{H}^{c}\right)\right)$ when $4.7159<$ $\bar{\theta} / \underline{\theta} \leq 4.7229$, while $\pi_{L}^{c}\left(s_{L}^{c}\left(s_{H}^{c}\right)\right)<\pi_{L}^{* *}\left(s_{L}^{* *}\left(s_{H}^{c}\right)\right)$ when $4.7229<\bar{\theta} / \underline{\theta} \leq$ 4.7301. Thus, when $2<\bar{\theta} / \underline{\theta} \leq 4.7229$, the best reply of the low-quality firm is $s_{L}^{c}\left(\underline{s}_{H}^{c}\right)$ when the high-quality firm chooses $s_{H}^{c}$. Second, given $s_{L}^{c}$, when $2<\bar{\theta} / \underline{\theta} \leq 4+\left[3 /\left(\mu_{H}^{* *}-1\right)\right]=4.7153$, where $\mu_{H}^{* *}=s_{H}^{* *}\left(s_{L}^{c}\right) / s_{L}^{c}$, only $s_{H}^{c}\left(s_{L}^{c}\right)$ is defined, so the best reply of the high-quality firm is $s_{H}^{c}\left(s_{L}^{c}\right)$. When $4.7153=4+\left[3 /\left(\mu_{H}^{* *}-1\right)\right]<\bar{\theta} / \underline{\theta} \leq 4+\left[3 /\left(\mu_{H}^{c}-\right.\right.$ $1)]=4.7301$, where $\mu_{H}^{c}=s_{H}^{c}\left(s_{L}^{c}\right) / s_{L}^{c}$, both $s_{H}^{c}\left(s_{L}^{c}\right)$ and $s_{H}^{* *}\left(s_{L}^{c}\right)$ are defined, and $\pi_{H}^{c}\left(s_{H}^{c}\left(s_{L}^{c}\right)\right)>\pi_{H}^{* *}\left(s_{H}^{* *}\left(s_{L}^{c}\right)\right)$ when $4.7153<\bar{\theta} / \underline{\theta} \leq 4.7226$, while $\pi_{H}^{c}\left(s_{H}^{c}\left(s_{L}^{c}\right)\right)<\pi_{H}^{* *}\left(s_{H}^{* *}\left(s_{L}^{c}\right)\right)$ when $4.7226<\bar{\theta} / \underline{\theta} \leq 4.7301$. Thus, when $2<\theta / \underline{\theta} \leq 4.7226$, the best reply of the high-quality firm is $s_{H}^{c}\left(s_{L}^{c}\right)$ when the low-quality firm chooses $s_{L}^{c}$. Therefore, when $2<\bar{\theta} / \underline{\theta} \leq$ 4.7226, a covered market outcome with a corner solution in the price stage is a Nash equilibrium, in which the firms choose $s_{H}^{c}=s_{H}^{c}\left(s_{L}^{c}\right)$ and $s_{L}^{c}=s_{L}^{c}\left(s_{H}^{c}\right)$, respectively, as shown in (8), in the quality stage.

In the same fashion, for $\left(s_{H}^{* *}=s_{H}^{* *}\left(s_{L}^{* *}\right), s_{L}^{* *}=s_{L}^{* *}\left(s_{H}^{* *}\right)\right)$ and an uncovered market outcome to be an equilibrium, we have to show that neither firm will deviate from $s_{i}^{* *}\left(s_{j}^{* *}\right)$ to $s_{i}^{c}\left(s_{j}^{* *}\right)$ when the other firm chooses $s_{j}^{* *}$. By using simulations, we have the following findings. First, given $s_{H}^{* *}$, when $\bar{\theta} / \underline{\theta}>4+\left[3 /\left(\mu_{L}^{c}-1\right)\right]=4.7193$, where $\mu_{L}^{c}=s_{H}^{* *} / s_{L}^{c}\left(s_{H}^{* *}\right)$, only $s_{L}^{* *}\left(s_{H}^{* *}\right)$ is defined, so the best reply of the low-quality firm is $s_{L}^{* *}\left(s_{H}^{* *}\right)$. When $4.7057=4+\left[3 /\left(\mu_{L}^{* *}-1\right)\right]<\bar{\theta} / \underline{\theta} \leq 4+\left[3 /\left(\mu_{L}^{c}-\right.\right.$ $1)]=4.7193$, where $\mu_{L}^{* *}=s_{H}^{* *} / s_{L}^{* *}\left(s_{H}^{* *}\right)$, both $s_{L}^{* *}\left(s_{H}^{* *}\right)$ and $s_{L}^{c}\left(s_{H}^{* *}\right)$ are defined, and $\pi_{L}^{* *}\left(s_{L}^{* *}\left(s_{H}^{* *}\right)\right)<\pi_{L}^{c}\left(s_{L}^{c}\left(s_{H}^{* *}\right)\right)$ when $4.7057<\bar{\theta} / \underline{\theta}<4.7124$,

${ }^{16}$ When $4+\left[3 /\left(\mu_{H}^{* *}-1\right)\right]<\bar{\theta} / \underline{\theta} \leq 4+\left[3 /\left(\mu_{H}^{c}-1\right)\right]$, both $s_{H}^{c}\left(s_{L}\right)$ and $s_{H}^{* *}\left(s_{L}\right)$ are defined, and we will discuss this circumstance in the next paragraph.

(C) 2008 The Author. Journal compilation (C) 2008 Blackwell Publishing Ltd and the Board of Trustees of the Bulletin of Economic Research. 
while $\pi_{L}^{* *}\left(s_{L}^{* *}\left(s_{H}^{* *}\right)\right)>\pi_{L}^{c}\left(s_{L}^{c}\left(s_{H}^{* *}\right)\right)$ when $4.7124 \leq \bar{\theta} / \underline{\theta} \leq 4.7193$. Thus, when $\theta / \underline{\theta} \geq 4.7124$, the best reply of the low-quality firm is $s_{L}^{* *}\left(s_{H}^{* *}\right)$ when the high-quality firm chooses $s_{H}^{* *}$. Second, given $s_{L}^{* *}$, when $\bar{\theta} / \underline{\theta}>4+\left[3 /\left(\mu_{H}^{c}-1\right)\right]=4.7195$, where $\mu_{H}^{c}=s_{H}^{c}\left(s_{L}^{* *}\right) / s_{L}^{* *}$, only $s_{H}^{* *}\left(s_{L}^{* *}\right)$ is defined, so the best reply of the high-quality firm is $s_{H}^{* *}\left(s_{L}^{* *}\right)$. When $4.7057=4+\left[3 /\left(\mu_{H}^{* *}-1\right)\right]<\bar{\theta} / \underline{\theta} \leq 4+\left[3 /\left(\mu_{H}^{c}-\right.\right.$ $1)]=4.7195$, where $\mu_{H}^{* *}=s_{H}^{* *}\left(s_{L}^{* *}\right) / s_{L}^{* *}$, both $s_{H}^{* *}\left(s_{L}^{* *}\right)$ and $s_{H}^{c}\left(s_{L}^{* *}\right)$ are defined, and $\pi_{H}^{* *}\left(s_{H}^{* *}\left(s_{L}^{* *}\right)\right)<\pi_{H}^{c}\left(s_{H}^{c}\left(s_{L}^{* *}\right)\right)$ when $4.7057<\theta / \underline{\theta}<$ 4.7125, while $\pi_{H}^{* *}\left(s_{H}^{* *}\left(s_{L}^{* *}\right)\right)>\pi_{H}^{c}\left(s_{H}^{c}\left(s_{L}^{* *}\right)\right)$ when $4.7125 \leq \bar{\theta} / \underline{\theta} \leq$ 4.7195. Thus, when $\bar{\theta} / \underline{\theta} \geq 4.7125$, the best reply of the high-quality firm is $s_{H}^{* *}\left(s_{L}^{* *}\right)$ when the low-quality firm chooses $s_{L}^{* *}$. Therefore, when $\bar{\theta} / \underline{\theta} \geq 4.7125$, an uncovered market outcome is a Nash equilibrium, in which the firms choose $s_{H}^{* *}=s_{H}^{* *}\left(s_{L}^{* *}\right)$ and $s_{L}^{* *}=s_{L}^{* *}\left(s_{H}^{* *}\right)$, respectively, as shown in (3), in the quality stage.

Thus, we have the following proposition.

Proposition 2. Suppose that the market outcome is endogenous to the firms and the firms incur fixed costs of quality improvement. When $\bar{\theta} / \underline{\theta}>4.7226$, the market is uncovered at equilibrium. When $2<\bar{\theta} / \underline{\theta}<4.7125$, the market is covered at equilibrium with a corner solution in the price stage. When $4.7125 \leq \bar{\theta} / \underline{\theta} \leq 4.7226$, both an uncovered market outcome and a covered market outcome with a corner solution in the price stage are Nash equilibria.

Comparing our results with Wauthy (1996), we have the following new findings. First, with fixed costs of quality improvement, a covered market outcome with an interior solution in the price stage is not an equilibrium. This suggests that the analyses and results based on a covered market with an interior solution in the price stage should be interpreted cautiously. Second, when $4.7125 \leq \bar{\theta} / \underline{\theta} \leq 4.7226$, there are two Nash equilibrium market outcomes: an uncovered market and a covered market with a corner solution in the price stage. Third, the quality level of the highquality firm varies with the values of $\bar{\theta}$ and $\underline{\theta}$, and it is also dependent on the choice of the low-quality firm. However, in Wauthy (1996), the highquality firm always chooses the highest feasible quality independently of the low-quality firm's choice. Fourth, in the presence of fixed costs of quality improvement, the competition between the firms is more intense and the degree of product differentiation is much greater than that with zero costs. 17

We also have some important results different from Motta (1993). Assuming that the market is partially covered, Motta (1993) derives the

${ }^{17}$ The degree of product differentiation is $\mu^{* *}=5.2512$ and $\mu^{c} \geq 5.1085$ in an uncovered market and a covered market with a corner solution in the price stage, respectively. The counterparts in Wauthy (1996) are $\mu^{* *}=1.75$ and $1.5 \leq \mu^{c} \leq 2$.

(C) 2008 The Author. Journal compilation (C) 2008 Blackwell Publishing Ltd and the Board of Trustees of the Bulletin of Economic Research. 
equilibrium of the game and then imposes the condition (i.e., $\bar{\theta} / \underline{\theta}>$ 4.7057) to satisfy the assumption of partial market coverage. However, in the present model, the market outcome is endogenously determined by the firms, and we consider all possible market configurations for all values of $\bar{\theta} / \underline{\theta}$. Across the regions defining both cases I and II, if the market outcome is endogenous (rather than exogenous) to the firms, taking the other firm's quality $s_{j}$ as given, each firm has two strategies $\left(s_{i}^{* *}\left(s_{j}\right), s_{i}^{c}\left(s_{j}\right)\right)$ to choose in the quality stage. Unlike Motta (1993), we show that an uncovered market outcome is not a Nash equilibrium when $4.7057<\bar{\theta} / \underline{\theta}<4.7125$, for each firm has an incentive to deviate from it to a covered market. Moreover, an uncovered market outcome and a covered market outcome with a corner solution in the price stage are both Nash equilibria when $4.7125 \leq \bar{\theta} / \underline{\theta} \leq 4.7226$.

Since there exist two Nash equilibria when $4.7125 \leq \bar{\theta} / \underline{\theta} \leq 4.7226$, we investigate further to compare the equilibrium profits and the corresponding consumer surplus at each equilibrium market outcome for welfare consideration. When the two firms compete in an uncovered market, consumer surplus is given by

$$
\begin{aligned}
C S & =\int_{\hat{\theta}_{1}}^{\bar{\theta}}\left(\theta s_{H}-p_{H}\right) \mathrm{d} \theta+\int_{\hat{\theta}_{2}}^{\hat{\theta}_{1}}\left(\theta s_{L}-p_{L}\right) \mathrm{d} \theta \\
& =\frac{1}{2} \bar{\theta}^{2} s_{H}-\bar{\theta} p_{H}+\frac{1}{2} \hat{\theta}_{1}^{2}\left(s_{H}-s_{L}\right)-\frac{1}{2} \hat{\theta}_{2}^{2} s_{L}+\hat{\theta}_{2} p_{L}
\end{aligned}
$$

Substituting $s_{H}^{* *}, s_{L}^{* *}, p_{H}^{* *}$ and $p_{L}^{* *}$ into (10), we have

$$
C S^{* *}=\frac{\theta^{4} \gamma^{4} \mu^{* * 4}\left(4 \mu^{* *}+5\right)\left(4 \mu^{* *}-7\right)}{2\left(4 \mu^{* *}-1\right)^{5}}
$$

When the market is covered, consumer surplus is given by

$$
\begin{aligned}
C S & =\int_{\hat{\theta}_{1}}^{\bar{\theta}}\left(\theta s_{H}-p_{H}\right) \mathrm{d} \theta+\int_{\underline{\theta}}^{\hat{\theta}_{1}}\left(\theta s_{L}-p_{L}\right) \mathrm{d} \theta \\
& =\frac{1}{2} \bar{\theta}^{2} s_{H}-\bar{\theta} p_{H}+\frac{1}{2} \hat{\theta}_{1}^{2}\left(s_{H}-s_{L}\right)-\frac{1}{2} \underline{\theta}^{2} s_{L}+\underline{\theta} p_{L}
\end{aligned}
$$

Substituting $s_{H}^{c}, s_{L}^{c}, p_{H}^{c}$ and $p_{L}^{c}$ into (11), we have

$$
\begin{aligned}
C S^{c}= & \frac{\theta^{4}}{16}\left[\gamma-1-\left(\frac{\mu^{c}(\gamma)}{\mu^{c}(\gamma)-1}\right)^{2}\right] \\
& \times\left[\gamma^{2}\left[\mu^{c}(\gamma)-1\right]+\frac{1}{\mu^{c}(\gamma)-1}+4 \gamma^{2}-6 \gamma+4\right]
\end{aligned}
$$

Since $\pi_{H}^{c}, \pi_{L}^{c}$ and $C S^{c}$ are implicit functions of $\bar{\theta} / \underline{\theta}$, we use numerical simulations to compare them with their counterparts $\pi_{H}^{* *}, \pi_{L}^{* *}$ and $C S^{* *}$.

(C) 2008 The Author. Journal compilation (C) 2008 Blackwell Publishing Ltd and the Board of Trustees of the Bulletin of Economic Research. 
When $4.7125 \leq \bar{\theta} / \underline{\theta} \leq 4.7226$, simulation results show that $\pi_{H}^{* *}>\pi_{H}^{c}$, $\pi_{L}^{* *}>\pi_{L}^{c}$ and $C S^{* *}>C S^{c}$. Therefore, we have the following proposition.

Proposition 3. When $4.7125 \leq \bar{\theta} / \underline{\theta} \leq 4.7226$, the equilibrium in an uncovered market yields higher producer surplus and consumer surplus than the one in a covered market with a corner solution in the price stage.

Comparing Bertrand competition and Cournot competition, Motta (1993) shows that Bertrand competition is more intense than Cournot competition, so the firms differentiate more under the former in order to relax the market competition. Harsher competition between the firms is more beneficial to consumers, leading to higher consumer surplus under Bertrand competition. Moreover, Motta (1993) shows the total profits are higher under Bertrand competition than under Cournot competition. Motta's results provide good intuitive explanations for Proposition 3. When the market is covered, the total quantity sold for the whole market is fixed, so the firms compete for the market share in a way similar to Cournot competition. Besides, with a corner solution in the price stage, the price of the low-quality firm is bounded with the constraint $p_{L}^{c}=\underline{\theta} s_{L}^{c}$. Thus, the price competition in a covered market is less intense than in an uncovered market. Harsher competition in an uncovered market benefits consumers more and generates higher consumer surplus, even though fewer consumers are served. The total profits are also higher in an uncovered market. Thus, social welfare, the sum of producer surplus and consumer surplus, is higher in an uncovered market than in a covered market.

\section{CONCLUSIONS}

This paper examines the market coverage in a duopoly model of vertical product differentiation. We assume that firms incur fixed costs to improve quality, and it is more costly to produce a higher quality. Unlike Wauthy (1996), we find that a covered market outcome with an interior solution in the price stage is not an equilibrium. Thus, the analyses and results based on this market configuration should be interpreted cautiously, otherwise they will be inappropriate and irrelevant. The market is uncovered at equilibrium when $\theta / \underline{\theta}>4.7226$, and the market is covered at equilibrium with a corner solution in the price stage when $2<\bar{\theta} / \underline{\theta}<4.7125$. When $4.7125 \leq \bar{\theta} / \underline{\theta} \leq 4.7226$, both market outcomes are Nash equilibria, but an uncovered market outcome yields higher social welfare than a covered market outcome with a corner solution in the price stage.

(C) 2008 The Author. Journal compilation (C) 2008 Blackwell Publishing Ltd and the Board of Trustees of the Bulletin of Economic Research. 


\section{REFERENCES}

Aoki, R. and Prusa, T. J. (1996). 'Sequential versus simultaneous choice with endogenous quality', International Journal of Industrial Organization, 15(1), pp. 103-21.

Boom, A. (1995). 'Asymmetric international minimum quality standards and vertical differentiation', Journal of Industrial Economics, 43(1), pp. 101-19.

Choi, C. J. and Shin, H. S. (1992). 'A comment on a model of vertical product differentiation', Journal of Industrial Economics, 40(2), pp. 229-31.

Crampes, C. and Hollander, A. (1995). 'Duopoly and quality standards', European Economic Review, 39(1), pp. 71-82.

Das, S. P. and Donnenfeld, S. (1989). 'Oligopolistic competition and international trade: quantity and quality restrictions', Journal of International Economics, 27(3-4), pp. 299-318.

Ecchia, G. and Lambertini, L. (1997). 'Minimum quality standards and collusion', Journal of Industrial Economics, 45(1), pp. 101-13.

Gabszewicz, J. and Thisse, J. F. (1979). 'Price competition, quality and income disparities', Journal of Economic Theory, 2(3), pp. 340-59.

Herguera, I., Kujal, P. and Petrakis, E. (2000). 'Quantity restrictions and endogenous quality choice', International Journal of Industrial Organization, 18(8), pp. 1259-77.

Herguera, I., Kujal, P. and Petrakis, E. (2002). 'Tariffs, quality reversals and exit in vertically differentiated industries', Journal of International Economics, 58(2), pp. 467-92.

Lehmann-Grube, U. (1997). 'Strategic choice of quality when quality is costly: the persistence of the high-quality advantage', RAND Journal of Economics, 28(2), pp. 372-84.

Lutz, S. (2000). 'Trade effects of minimum quality standards with and without deterred entry', Journal of Economic Integration, 15(2), pp. 314-44.

Lutz, S., Lyon, T. P. and Maxwell, J. W. (2000). 'Quality leadership when regulatory standards are forthcoming', Journal of Industrial Economics, 48(3), pp. 33149.

Maxwell, J. W. (1998). 'Minimum quality standards as a barrier to innovation', Economics Letters, 58(3), pp. 355-60.

Moorthy, K. S. (1988). 'Product and price competition in a duopoly', Marketing Science, 7(2), pp. 141-68.

Motta, M. (1993). 'Endogenous quality choice: price vs. quantity competition', Journal of Industrial Economics, 41(2), pp. 113-31.

Polavarapu, R. and Vaidya, A. (1996a). 'Commercial policy with vertical product differentiation', Journal of Economic Integration, 11(2), pp. 230-47.

Polavarapu, R. and Vaidya, A. (1996b). 'Optimal trade policy with quality differentiated goods', International Trade Journal, 10(3), pp. 379-406.

Ronnen, U. (1991). 'Minimum quality standards, fixed costs, and competition', RAND Journal of Economics, 22(4), pp. 490-504.

Shaked, A. and Sutton, J. (1982). 'Relaxing price competition through product differentiation', Review of Economic Studies, 49(1), pp. 3-13.

Tirole, J. (1988). The Theory of Industrial Organization, Cambridge, MA: MIT Press. 
Valletti, T. M. (2000). 'Minimum quality standards under Cournot competition', Journal of Regulatory Economics, 18(3), pp. 235-45.

Wang, X. H. (2003). 'A note on the high-quality advantage in vertical differentiation models', Bulletin of Economic Research, 55(1), pp. 91-9.

Wang, X. H. and Yang, B. Z. (2001). 'Mixed-strategy equilibria in a quality differentiation model', International Journal of Industrial Organization, 19(12), pp. 213-26.

Wauthy, X. (1996). 'Quality choice in models of vertical differentiation', Journal of Industrial Economics, 44(3), pp. 345-53.

Zhou, D., Spencer, B. J. and Vertinsky, I. (2002). 'Strategic trade policy with endogenous choice of quality and asymmetric costs', Journal of International Economics, 56(1), pp. 205-32.

\section{APPENDIX A}

To derive the equilibrium prices in the second stage when the market is covered, we first derive the best price responses of each firm to the price set by its rival. The condition for a covered market in which both the high-quality and low-quality firms supply a positive quantity of output and every consumer consumes either good is $p_{L} / s_{L} \leq \underline{\theta}<$ $\left(p_{H}-p_{L}\right) /\left(s_{H}-s_{L}\right)<\bar{\theta}$. Taking $\left(s_{H}, s_{L}\right)$ as given, the firms choose prices to maximize their own profits, which are given by

$$
\begin{aligned}
\pi_{H} & =\left[\bar{\theta}-\frac{p_{H}-p_{L}}{s_{H}-s_{L}}\right] p_{H}-\frac{1}{2} s_{H}^{2} \\
\pi_{L} & =\left[\frac{p_{H}-p_{L}}{s_{H}-s_{L}}-\underline{\theta}\right] p_{L}-\frac{1}{2} s_{L}^{2}
\end{aligned}
$$

From the first-order conditions, we have the reaction functions of the firms as follows:

$$
\begin{gathered}
p_{H}\left(p_{L}\right)=\frac{1}{2}\left[p_{L}+\bar{\theta}\left(s_{H}-s_{L}\right)\right] \\
p_{L}\left(p_{H}\right)= \begin{cases}\frac{1}{2}\left[p_{H}-\underline{\theta}\left(s_{H}-s_{L}\right)\right] & \text { if } p_{L} / s_{L}<\underline{\theta} \\
\underline{\theta} s_{L} & \text { if } p_{L} / s_{L} \geq \underline{\theta}\end{cases}
\end{gathered}
$$

The reaction function of the low-quality firm has to be bounded by the condition $p_{L} / s_{L} \leq \underline{\theta}$ for a covered market. Solving the two reaction functions simultaneously, we have the following two solutions.

(1) Interior solution: $p_{H}^{*}=(2 \bar{\theta}-\underline{\theta})\left(s_{H}-s_{L}\right) / 3, p_{L}^{*}=(\bar{\theta}-2 \underline{\theta})$ $\times\left(s_{H}-s_{L}\right) / 3$ if $2<\bar{\theta} / \underline{\theta}<2+[3 /(\mu-1)] \quad$ (so that the condition $p_{L}^{*} / s_{L}<\underline{\theta}$ is fulfilled).

(2) Corner solution: $p_{L}^{c}=\underline{\theta} s_{L}$ and $p_{H}^{c}=\left[\underline{\theta} s_{L}+\bar{\theta}\left(s_{H}-s_{L}\right)\right] / 2$ if $2+[3 /(\mu-1)] \leq \bar{\theta} / \underline{\theta} \leq 4+[3 /(\mu-1)]$. That is, when $p_{L}^{* *} / s_{L} \leq \underline{\theta}$ and $p_{L}^{*} / s_{L} \geq \underline{\theta}$, under an uncovered market 


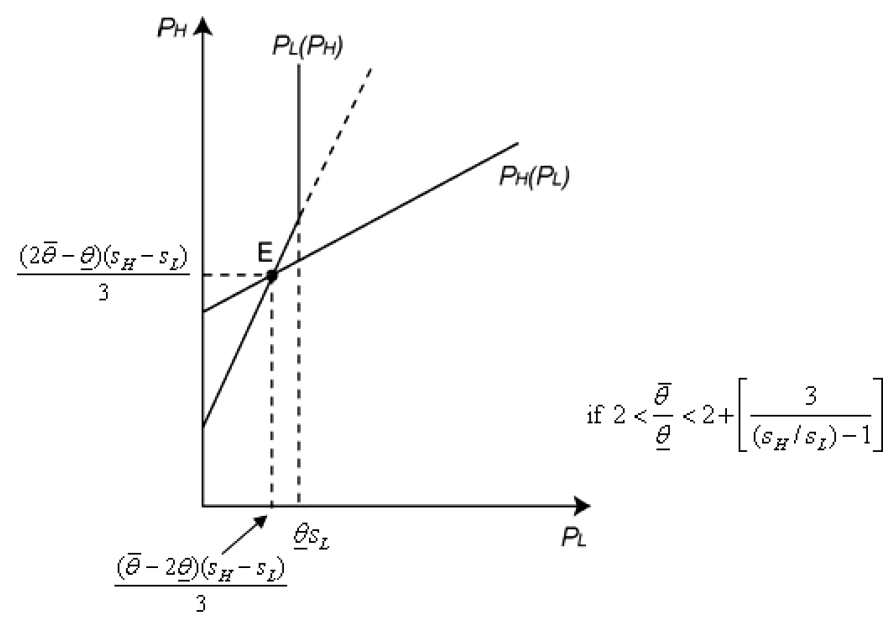

Fig. 1. The interior solution in the price stage for a covered market.

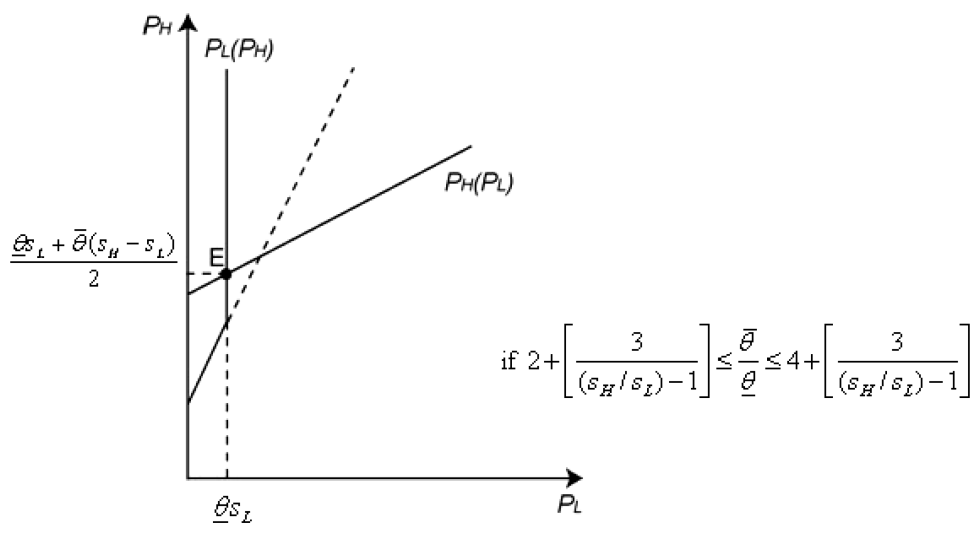

Fig. 2. The corner solution in the price stage for a covered market.

assumption, $\partial \pi_{L} / \partial p_{L}<0$ at $p_{L}=\underline{\theta} s_{L}$, while under a covered market assumption, $\partial \pi_{L} / \partial p_{L}>0$ at $p_{L}=\underline{\theta} s_{L}$. The solutions in an uncovered market (Case I) and a covered market with an interior solution (Case III) are not feasible. Thus, a corner solution prevails where the low-quality firm sets $p_{L}^{c}=\underline{\theta} s_{L}$ so that $p_{L}^{c} / s_{L}=\underline{\theta}$, and the high-quality firm sets $p_{H}^{c}=\left[\underline{\theta} s_{L}+\bar{\theta}\left(s_{H}-s_{L}\right)\right] / 2$ accordingly.

Figures 1 and 2 illustrate the interior and corner solutions respectively in the price stage for a covered market. Taking $\left(s_{H}, s_{L}\right)$ as given, $p_{H}\left(p_{L}\right)$ and $p_{L}\left(p_{H}\right)$ are the reaction functions of the high-quality and low-quality firms, respectively. The Nash equilibrium is at point $\mathrm{E}$, at which $p_{H}\left(p_{L}\right)$ and $p_{L}\left(p_{H}\right)$ intersect. 
APPENDIX B

To compare $s_{L}^{*}\left(s_{H}^{*}\right)$ and $s_{L}^{c}\left(s_{H}^{*}\right)$, evaluating (6) at $s_{L}=s_{L}^{*}\left(s_{H}^{*}\right)=[(2 \bar{\theta}-$ $\left.\underline{\theta})^{2}(\bar{\theta}-2 \underline{\theta})\right] /[9(\hat{\theta}+\underline{\theta})]$ yields

$$
\begin{aligned}
& \frac{\left[\underline{\theta}(\bar{\theta}-\underline{\theta})\left(s_{H}^{*}-s_{L}^{*}\left(s_{H}^{*}\right)\right)^{2}-\underline{\theta}^{2} s_{H}^{* 2}\right]}{2\left(s_{H}^{*}-s_{L}^{*}\left(s_{H}^{*}\right)\right)^{2}}-s_{L}^{*}\left(s_{H}^{*}\right) \\
& =\frac{\underline{\theta}(\bar{\theta}-\underline{\theta})}{2}-\frac{(\bar{\theta}+\underline{\theta})^{2}}{18}-\frac{(2 \bar{\theta}-\underline{\theta})^{2}(\bar{\theta}-2 \underline{\theta})}{9(\bar{\theta}+\underline{\theta})} \\
& =-\frac{\bar{\theta}^{2}-7 \bar{\theta} \underline{\theta}+10 \underline{\theta}^{2}}{18}-\frac{(2 \bar{\theta}-\underline{\theta})^{2}(\bar{\theta}-2 \underline{\theta})}{9(\bar{\theta}+\underline{\theta})} \\
& =-\frac{(\bar{\theta}-2 \underline{\theta})(\bar{\theta}-5 \underline{\theta})}{18}-\frac{(2 \bar{\theta}-\underline{\theta})^{2}(\bar{\theta}-2 \underline{\theta})}{9(\bar{\theta}+\underline{\theta})} \\
& =-\frac{\bar{\theta}-2 \underline{\theta}}{18(\bar{\theta}+\underline{\theta})}\left[(\bar{\theta}-5 \underline{\theta})(\bar{\theta}+\underline{\theta})+2(2 \bar{\theta}-\underline{\theta})^{2}\right] \\
& =-\frac{(\bar{\theta}-2 \underline{\theta})\left(3 \bar{\theta}^{2}-4 \bar{\theta} \underline{\theta}-\underline{\theta}^{2}\right)}{6(\bar{\theta}+\underline{\theta})} \\
& <0
\end{aligned}
$$

where $(\bar{\theta}-2 \underline{\theta})\left(3 \bar{\theta}^{2}-4 \bar{\theta} \underline{\theta}-\underline{\theta}^{2}\right)>0$ when $\bar{\theta} / \underline{\theta}>2$. Thus, $\partial \pi_{L}^{c} /\left.\partial s_{L}\right|_{s_{L}=s_{L}^{*}\left(s_{H}^{*}\right)}<0$, implying that $s_{L}^{*}\left(s_{H}^{*}\right)>s_{L}^{c}\left(s_{H}^{*}\right)$.

\section{APPENDIX C}

Substituting $s_{L}^{*}\left(s_{H}\right)=s_{H}(\bar{\theta}-2 \underline{\theta}) /(\bar{\theta}+\underline{\theta})$ into (4) yields

$$
\begin{aligned}
\pi_{L}^{c}\left(s_{L}^{*}\left(s_{H}\right)\right) & =\frac{\underline{\theta} s_{H}\left(\frac{\bar{\theta}-2 \theta}{\bar{\theta}+\underline{\theta}}\right) s_{H}\left[\bar{\theta}-2 \underline{\theta}-\frac{(\bar{\theta}-\underline{\theta})(\bar{\theta}-2 \underline{\theta})}{\bar{\theta}+\underline{\theta}}\right]}{2 s_{H}\left(\frac{3 \underline{\theta}}{\bar{\theta}+\underline{\theta}}\right)}-\frac{1}{2} s_{H}^{2} \frac{(\bar{\theta}-2 \underline{\theta})^{2}}{(\bar{\theta}+\underline{\theta})^{2}} \\
& =\frac{s_{H} \underline{\theta}(\bar{\theta}-2 \underline{\theta})^{2}}{3(\bar{\theta}+\underline{\theta})}-\frac{1}{2} s_{H}^{2} \frac{(\bar{\theta}-2 \underline{\theta})^{2}}{(\bar{\theta}+\underline{\theta})^{2}} \\
& =\frac{s_{H}(\bar{\theta}-2 \underline{\theta})^{2}}{6(\bar{\theta}+\underline{\theta})^{2}}\left[2 \underline{\theta}(\bar{\theta}+\underline{\theta})-3 s_{H}\right]
\end{aligned}
$$

(C) 2008 The Author. Journal compilation (C) 2008 Blackwell Publishing Ltd and the Board of Trustees of the Bulletin of Economic Research. 
Substituting $s_{L}^{*}\left(s_{H}\right)=s_{H}(\bar{\theta}-2 \underline{\theta}) /(\bar{\theta}+\underline{\theta})$ into (9) yields

$$
\begin{aligned}
\pi_{L}^{*}\left(s_{L}^{*}\left(s_{H}\right)\right) & =\frac{(\bar{\theta}-2 \underline{\theta})^{2} s_{H}\left(\frac{3 \underline{\theta}}{\bar{\theta}+\underline{\theta}}\right)}{9}-\frac{1}{2} s_{H}^{2} \frac{(\bar{\theta}-2 \underline{\theta})^{2}}{(\bar{\theta}+\underline{\theta})^{2}} \\
& =\frac{s_{H} \underline{\theta}(\bar{\theta}-2 \underline{\theta})^{2}}{3(\bar{\theta}+\underline{\theta})}-\frac{1}{2} s_{H}^{2} \frac{(\bar{\theta}-2 \underline{\theta})^{2}}{(\bar{\theta}+\underline{\theta})^{2}} \\
& =\frac{s_{H}(\bar{\theta}-2 \underline{\theta})^{2}}{6(\bar{\theta}+\underline{\theta})^{2}}\left[2 \underline{\theta}(\bar{\theta}+\underline{\theta})-3 s_{H}\right]
\end{aligned}
$$

Thus, $\pi_{L}^{c}\left(s_{L}^{*}\left(s_{H}\right)\right)=\pi_{L}^{*}\left(s_{L}^{*}\left(s_{H}^{*}\right)\right)$. Given any $s_{H}$, since $s_{L}^{c}\left(s_{H}\right)$ maximizes $\pi_{L}^{c}, \pi_{L}^{c}\left(s_{L}^{c}\left(s_{H}\right)\right)>\pi_{L}^{c}\left(s_{L}^{*}\left(s_{H}\right)\right)$, so $\pi_{L}^{c}\left(s_{L}^{c}\left(s_{H}\right)\right)>\pi_{L}^{c}\left(s_{L}^{*}\left(s_{H}\right)\right)=$ $\pi_{L}^{*}\left(s_{L}^{*}\left(s_{H}\right)\right)$.

\section{APPENDIX D}

To compare $s_{H}^{*}\left(s_{L}\right)$ and $s_{H}^{c}\left(s_{L}\right)$, evaluating (5) at $s_{H}=s_{H}^{*}\left(s_{L}\right)=(2 \bar{\theta}-$ $\underline{\theta})^{2} / 9$ yields

$$
\begin{aligned}
& \frac{\bar{\theta}^{2}\left(s_{H}^{*}\left(s_{L}\right)-s_{L}\right)^{2}-\underline{\theta}^{2} s_{L}^{2}}{4\left(s_{H}^{*}\left(s_{L}\right)-s_{L}\right)^{2}}-s_{H}^{*}\left(s_{L}\right) \\
& =\frac{\bar{\theta}^{2}}{4}-\frac{(2 \bar{\theta}-\underline{\theta})^{2}}{9}-\frac{\underline{\theta}^{2} s_{L}^{2}}{4\left(s_{H}^{*}\left(s_{L}\right)-s_{L}\right)^{2}} \\
& \quad=-\frac{(7 \bar{\theta}-2 \underline{\theta})(\bar{\theta}-2 \underline{\theta})}{36}-\frac{\underline{\theta}^{2} s_{L}^{2}}{4\left(s_{H}^{*}\left(s_{L}\right)-s_{L}\right)^{2}} \\
& \quad<0
\end{aligned}
$$

Thus, $\partial \pi_{H}^{c} /\left.\partial s_{H}\right|_{s_{H}=s_{H}^{*}\left(s_{L}\right)}<0$, implying that $s_{H}^{*}\left(s_{L}\right)>s_{H}^{c}\left(s_{L}\right)$. 